\title{
COVID-19 and social protection of poor and vulnerable groups in Latin America: a conceptual framework
}

\author{
Nora Lustig and Mariano Tommasi
}

\begin{abstract}
The growing crisis caused by the coronavirus disease pandemic has dire implications for Latin American societies. As is often the case, the most vulnerable sectors of society - especially those living in extreme poverty - are being hit the hardest. This article identifies strategies and specific responses designed to achieve three goals: (i) reduce epidemiological risks to save lives; (ii) protect livelihoods; and (iii) ensure human capital accumulation. Epidemiological externalities, as well as humanitarian concerns, demand universal social inclusion. In order to protect the lives, health, livelihoods and human capital of the poor and vulnerable, it will be essential to: implement targeted and decisive interventions at the local level that go beyond transferring cash; allocate adequate resources to fund income support and other key interventions; and involve on local actors and grass-roots organizations for the interventions to be effective.
\end{abstract}

\section{Keywords}

COVID-19, viruses, epidemics, social aspects, social security, poverty, socially disadvantaged persons, income, health, education, social conditions, social policy, Latin America

\section{JEL classification}

C63, D31, I32, 138

\section{Authors}

Nora Lustig is Samuel Z. Stone Professor of Latin American Economics at the Commitment to Equity Institute (CEQI), Tulane University, United States. Email: nlustig@tulane.edu.

Mariano Tommasi works at the Centro de Estudios para el Desarrollo Humano (CEDH), Universidad de San Andrés, Argentina. Email: tommasi@udesa.edu.ar. 


\section{Introduction ${ }^{1}$}

The global coronavirus disease (COVID-19) pandemic, along with foreign and domestic responses to it, have taken a huge toll on society as a whole in terms of lives and economic losses. Even if Latin America had been miraculously spared by the pandemic, the adverse external shocks (falling demand for exports and tourism, declining commodity prices and unprecedented capital outflows) would have hurt the region's countries significantly. The pandemic and the measures designed to contain it compound the negative impact on living standards in ways that are still being assessed, given the uncertainty surrounding the dynamics of the pandemic.

Although every level of society has been affected, the intensity of impact has varied widely across social groups. The pandemic is further impoverishing the poor and exacerbating inequality. Informal workers are severely affected by the lockdown measures. Low-skilled workers are not able to work from home. The poor and the vulnerable ${ }^{2}$ are being hit the hardest because their living conditions and future opportunities are threatened by economic dislocations and other negative effects of the pandemic. As the virus spread from more affluent districts where it first arrived, it began to take hold among populations that live in poorer sanitary conditions and suffer from multiple disadvantages that are magnified due to lockdown.

The current situation calls for urgent actions on multiple connected fronts: (i) the epidemiological, health care and sanitation front; (ii) the economic front; (iii) the labour market front; and (iv) the social protection front. This paper focuses on one important component of the social protection front, which is to identify strategies capable of achieving three goals for those living in poverty and vulnerable situations: (i) reduce epidemiological risks to save lives; (ii) protect livelihoods; and (iii) protect and secure human capital accumulation. The aim of the paper is to provide a conceptual framework to guide policy design.

The complex vector of shocks induced by the pandemic decreases the income of most people. Among other things, for given poverty lines it will increase the number of people living in poverty in official statistics. A recent report by the Economic Commission for Latin America and the Caribbean (ECLAC) estimates this number of "new poor" to be in the order of 45 million people (ECLAC, 2020b). Current macroeconomic and other measures are (should be) attempting to soften the downward pressure on the income curve. A number of measures are (should be) devoted to soften the employment and income blow on many affected individuals, and particularly those at risk of falling into poverty. However, those who were already living in poverty are at risk of suffering great income losses, in some cases pushing a number of them below the extreme-poverty line. According to ECLAC, nearly 29 million people could join the ranks of those living in extreme poverty in 2020 as a result of the pandemic (ECLAC, 2020b). People living in poverty should definitely be given priority when it comes to income support, but that will not be enough to effectively protect their lives, livelihoods and human capital. These individuals, the chronic poor, do not only experience income poverty. They also tend to: live in overcrowded homes, lack basic social services, receive poor health care and education and face various forms of discrimination. This group includes residents of urban slums and other areas of concentrated poverty, undocumented migrants and indigenous communities. Within these groups, children, women, older adults, the differently-abled and those belonging to groups such as lesbian, gay, bisexual, transgender, queer and intersex (LGBTQI) face even greater challenges.

\footnotetext{
1 This paper is based on a longer version (see Lustig and Tommasi (2020)), which includes the complete set of background material and references. Among other things, this paper includes updates to reflect the rapid changes the region experienced as a result of the coronavirus disease (COVID-19). We would like to thank Mart Trasberg for his help with this task.

2 In some economics literature, the word "vulnerable" is used to refer to people whose income is above the poverty line but are at risk of falling into poverty if faced with an adverse shock. Here, we are not using the term in that way, but in the standard dictionary sense of a person in need of special care, support or protection because of age, disability or risk of abuse/neglect.
} 
Paying special attention to those living in poverty and vulnerable situations in the policy response is crucial for three main reasons. First, because this group is already suffering from multiple disadvantages, there is an ethical imperative to prioritize their needs - as they are the ones who can least afford to be hit by the multiple negative shocks detonated by the pandemic. Second, the negative effects on this group are likely to have a long-lasting impact. Modern development literature emphasizes the permanent effects that temporary shocks can have on the lives of infants, children, teenagers and women. Circumstances such as child malnutrition, school dropout and traumatic experiences at some point in life often have irreversible effects.

In a pandemic, there is a crucial third reason to prioritize those living in poverty and vulnerable situations. As the virus spreads rapidly, those with more precarious day-to-day realities not only face a greater risk of infection but are also a plausible source of transmission. If these groups are not at least partially compensated for their income loss during lockdowns, it will be very difficult for them to comply with the restrictions. If tests or the eventual vaccine are not made widely available and at no (or very low) cost, the poor and vulnerable are likely to choose not to be tested or vaccinated. This externality is one of the main arguments in favour of prioritizing these groups within the context of a pandemic. During the pandemic, "forgetting" to protect certain sectors of society (such as slum-dwellers, the homeless, undocumented migrants or the transsexual population, to name but a few) can severely hinder the ability to contain the spread of the virus. During a pandemic, universal social protection becomes a precondition to successfully combating the spread of the disease.

\section{COVID-19 exacerbates pre-existing inequalities and vulnerabilities}

\section{Groups at risk of infection, illness and death}

While the initial number of infections and deaths in the region was relatively low, Latin America has now emerged as one of the hotspots of COVID-19. At the time of writing, Argentina, Brazil, Colombia, Mexico and Peru are among the top 10 countries in terms of infections; and Brazil, Colombia, Mexico and Peru are among the top 10 in terms of deaths per 100,000 inhabitants (CRC, 2020). ${ }^{3}$ Older adults and individuals with pre-existing health conditions are the two main groups at risk of contracting and succumbing to COVID-19. As for age, the share of older adults in the population of Latin America is not large (less than 9\%) (CEDLAS/World Bank, 2020). Regarding pre-existing conditions, however, the situation is worrisome. Excess weight and obesity are very prevalent in Latin America (nearly $60 \%$ of the population), and $10 \%$ of the population suffers from diabetes (PAHO, 2020). Also, the very poor sanitary conditions in the slums and other poor neighbourhoods of Latin America make them a particular focus of concern.

\section{Multiple deprivations}

Using the international poverty indicator of US $\$ 5.50$ per day (expressed in terms of purchasing power parity), the poverty rate in Latin America before COVID-19 was $23 \%$. Nearly $4 \%$ of Latin Americans lived in extreme poverty (namely, those at or below the US\$1.90/day poverty line), and did not earn enough to purchase the minimum amount of food to have adequate nutrition. In Latin America, 10\% of the population (delineated by the US\$3.20/day poverty line) were at risk of falling into extreme poverty.

\footnotetext{
3 Also, projections by the Institute for Health Metrics and Evaluation (IHME) released on 25 June 2020 estimated that, by October 1 , total deaths due to COVID-19 in Latin America and the Caribbean would reach almost 440,000 (IHME, 2020).
} 
This percentage was notably higher in some Latin American countries such as the Plurinational State of Bolivia, Guatemala and Ecuador (CEDLAS/World Bank, 2020; ECLAC, 2020a).

Income poverty is only the tip of the iceberg in terms of the lives of the chronic poor, however. For most of the population in question, poverty is a living condition that implies disadvantages in multiple dimensions. Over $80 \%$ of those included in the poorest quintile of income distribution work in the informal sector and therefore have no access to unemployment insurance, contributory pensions or other benefits. In Latin America, 22\% of people lack access to safe drinking water; $34 \%$ do not have an Internet connection, which is so essential in these circumstances; and $45 \%$ do not have a bank account. While the severity of poverty is higher in rural areas, about two thirds of the poor live in urban areas. This seems to be the sector where the pandemic is hitting the hardest. Over $20 \%$ of urban residents live in slums, where conditions in terms of overcrowding and poor habitat are extreme (CEDLAS/World Bank, 2020; ECLAC, 2020a).

\section{The COVID-19 shock interacts with existing inequalities and vulnerabilities}

All of the above-mentioned disadvantages that give rise to multidimensional poverty interact with the conditions generated by the pandemic to create a potentially vicious cycle. Many of these vulnerabilities make people more likely to get infected by the coronavirus, and many of the effects of the pandemic exacerbate the suffering produced by deprivation.

For example, living in slums makes people more susceptible to infection and serious illness because of overcrowded spaces and lack of access to water and sanitation. Labour market informality is a key aspect of poor and vulnerable people's lives, and it amplifies the effects of the sharp income decline produced by the pandemic - particularly for people who own few or no assets. In most of the region's countries, informal workers have no social protection whatsoever. The poor are not only unlikely to have a job that can be performed remotely, but it would also be difficult for them to do so given the conditions of their homes and the lack of infrastructure (including an Internet connection). ${ }^{4}$ This feeds into whether it is possible to "stay home." If the poor lack the means to satisfy their basic needs in the short term, they cannot follow the rules of social isolation. They cannot stay at home if that prevents them from procuring their daily sustenance.

Staying at home means enduring a number of hardships caused by overcrowding, lack of basic services and the suboptimum environments in which homes are located. In addition, education and trustworthy sources of information are less likely to reach these families, as they lack the tools necessary for connectivity. Staying at home could breed other health issues, especially given the current health sector scenario in which issues unrelated to coronavirus are not receiving proper attention. The confinement, boredom, uncertainty and fear associated with lockdown measures could aggravate family dysfunction that, in extreme cases, exacerbates violence in the home and child abuse.

Some of the main vicious-cycle dynamics arising from the combined effect of containment policies and economic fallout include those affecting the human capital of children. In particular, undernutrition in utero and in the early stages of life is likely to increase as a result of lower incomes. Second, school closures are likely to deeply affect the children of poor households that may find it extremely difficult (if not impossible) to continue their education at home due to lack of adequate equipment, connectivity and -above all - coaching. Children are quite likely to end up with lower achievements and many might drop out of school altogether. This year may end up featuring the largest loss of human capital in modern history. That loss will be distributed very unfairly, with the most vulnerable bearing the brunt of this cost.

\footnotetext{
4 The same applies to schooling. The educational disadvantages experienced by poor children are worsening, as they are isolated in their unconnected homes with their uneducated parents.
} 


\section{A brief profile of the vulnerable groups}

As we said in the introduction, our goal is to provide a conceptual framework for an effective policy response to protect the health and lives, livelihoods and human capital of the poor and vulnerable. Defining the income poor is straightforward: anybody whose income is below the country's poverty line is classified as poor. Helping families living in poverty cope with income losses during the pandemic is also straightforward: governments should expand existing cash transfer programmes (or add new ones). At least 15 States introduced new social assistance programmes in the first few months of lockdown, and most have also expanded existing schemes.

However, we argue that other forms of deprivation - beyond lack of sufficient income - require equal attention. Violence at the hands of a domestic partner or discrimination in the health system because of skin colour, sexual orientation or migratory status are disadvantages that have been exacerbated during the pandemic. These dysfunctional behaviours cannot be combated simply through cash transfers. Similarly, the difficulties of poor children in slums continuing their education during shutdowns cannot be solved with cash transfers. Cash transfers will not produce the type of coaching children need for effective home schooling. The design of an effective policy response therefore must involve an identification of the vulnerable groups and their particular circumstances. Below, we provide an overview of some of the main vulnerable groups.

- Urban poor. The urban poor, especially those living in slums, are facing a high-stake situation in terms of epidemiological risk, their livelihoods, their human capital and life conditions. They overlap with various other categories of deprivation. ${ }^{5}$ They are largely informal workers with no assets or social security. They live in overcrowded homes without water or sanitation. A large proportion of them have no access to the Internet. They face pre-existing health issues. Most of them do not have access to the banking system. Various family dysfunctions are commonplace, and under lockdown these can get magnified to the point of domestic violence and child abuse. For this group, staying at home is extremely difficult.

- Women. Most women are involved in the service sector, which has been especially hard hit by physical distancing measures. Women are the heads of many single-parent households, which are at greater risk - making women more vulnerable to financial instability. Women throughout the region are responsible for the bulk of domestic chores, which in many cases have increased due to quarantine. Women are the main victims of violence in the home, and abuse has worsened as quarantine has forced families to lock down together - thereby raising tensions amongst household members. Additional frictions arise as families struggle to make ends meet. Even before the advent of COVID-19, 15\% of Latin American women had reported suffering from domestic violence (UN-Women, 2020).

- Children. There are more than 150 million children in Latin America. Nearly half of them are living in poverty. Even without reference to extreme cases such as children who live on the streets, many of these children are extremely vulnerable in normal times, and even more so at the moment. There are children who can end up alone due to the illness or death of a sole caregiver. Many children see their living conditions worsen due to their parents' income problems. High numbers of children are facing difficulties in receiving care in the current circumstances. Poor children's schooling is interrupted because of school closures. Many young people face several of these risks and disadvantages at the same time. Especially for young children, any of these temporary situations might have permanent effects.

\footnotetext{
5 Many of the conditions we describe here apply also to rural poverty.
} 
- Older persons. Besides having the highest chance of dying of COVID-19, older persons also stand out as a vulnerable group from a social perspective. They are highly dependent on others, as they are not experienced in handling technology or communication tools. Some of them live alone and have difficulties accessing food, medical care and medicines because of the lockdowns.

- Indigenous people. Latin America has almost 50 million inhabitants who belong to indigenous communities (from over 500 different ethnicities). These communities account for $8 \%$ of the total population of the region, $14 \%$ of the population living in poverty and $17 \%$ of those living in extreme poverty (Albertos, 2018). In terms of their relationship with the labour market, indigenous people tend to work in precarious, low-skilled jobs. Indigenous communities also have restricted access to education and have first-hand experience of the negative impacts of climate change. Moreover, they lack access to medical centres and basic sanitation, and they have very poor health conditions compared to non-indigenous people with similar characteristics.

- Migrants. Migrants, especially undocumented ones, often suffer marginalization and discrimination. They tend to work in the service sector - especially in the hospitality industrywhich has been hit particularly hard. Unless they are long-term permanent residents, migrants are not entitled to receive benefits from cash transfer and other programmes. Complying with lockdowns therefore becomes an impossible task, since there is no safety net for these groups. This is problematic because these very groups become natural carriers of the disease and can trigger new outbreaks. The problem is compounded because, in some countries, undocumented migrants have no access to the health-care system.

- Other vulnerable groups. The "forgotten" and excluded population also includes other groups: for instance, the homeless, prison population, sex workers and transgender individuals. In designing policies to contain the spread of the virus and mitigate the impact of the ensuing economic crisis, policymakers must be as inclusive as possible. The overriding guiding principle should be as stated in the introduction: universal social protection (in a multidimensional sense) as a precondition to successfully combatting the spread of the disease.

\section{Impact of lockdown measures on those living in poverty and vulnerable situations}

\section{Income}

While there are no official data yet on the effect of COVID-19 on poverty and inequality, microsimulations provide a glimpse of the potential impacts. Lustig and others (2020) estimate the impact of COVID- induced lockdown policies in Argentina, Brazil, Colombia and Mexico. Lockdown measures have a large impact on income poverty: the rise in the number of people living in poverty in these four countries (without factoring in social assistance) varies between 23.3 million and 30.4 million depending on the scenario. The authors do not assume that the income losses are proportionally equal across the income distribution, which makes the simulated effect larger than some previous estimations. Contrary to prior expectations, Lustig and others find that the worst effects are not on the poorest but those (roughly) in the middle of the income distribution. This is because the social assistance policies implemented by most Latin American countries over the past 25 years mitigate effects on falls in the incomes of the poorest. The analysis also shows that the substantial expansion 
of existing social assistance or entirely new programmes (Argentina and Brazil) is potentially offsetting a significant share of the poverty caused by the crisis. ${ }^{6}$

\section{Multidimensional deprivation}

To prevent the virus from spreading unchecked and -in the absence of robust testing, tracing and isolating capacity - all Latin American countries have implemented full or targeted lockdowns (quarantines). A survey carried out in poor urban neighbourhoods in Argentina and brief reports from United Nations Development Programme (UNDP) country offices on another 12 countries offered early evidence on the effects of lockdown measures on the poor and vulnerable (Kessler, 2020).

First, 8 of the 13 countries named health-related issues among the main concerns. Usual services have been restricted and there are major obstacles when it comes to accessing much-needed medication and prescriptions. Second, in 5 of the 13 countries, increasing domestic violence - both on the streets and inside households - was identified among the main concerns. This is made worse by the high levels of alcohol and drug consumption.

Third, access to food emerged as a major issue. Neighbourhood grocery stores frequented by the poor population lack adequate supplies, and this combines with sharp price increases and falling incomes. It is difficult for non-governmental organizations (NGOs), churches and other local social actors to keep their usual operations running under current circumstances. Other issues identified included discrimination and exclusion of minorities, migrants and members of the LGBTQI community; overcrowding; and unequal access to online learning.

Virtual classes are not available to everyone, as connectivity services are unevenly distributed in these neighbourhoods. Since young people have not been able to begin the academic year properly, their situation has deteriorated. Dropping out of school is a frequent phenomenon, and such temporary circumstances might have permanent effects for children and adolescents on the edge of society.

There is some evidence about the impact of COVID-19 on other, non-income dimensions such as nutrition, health, school enrolment and learning outcomes. The World Food Programme (WFP, 2020) estimates that the total number of people in severe food insecurity could increase from 3.4 million in 2019 to about 16 million in 2020 due to COVID-19 in the region. School feeding programmes are a crucial component of policies to ensure the right to food, and an estimated 65 million schoolchildren have had their usual form of food delivery affected because of school closures (FAO/ECLAC, 2020). While children were expected to complete 7.7 years of schooling prior to the pandemic in Latin America and Caribbean, the simulations conducted by Azevedo and others (2020) suggest that lockdowns could lower schooling to 7.4 years in the optimistic scenario (schools are closed for 3 months of a 10-month school year) and to 6.8 years in the pessimistic scenario (schools are closed for 7 months). Under the Programme for International Student Assessment (PISA), the average score in the region is expected to decrease from 402 to 396 in the optimistic scenario and to 376 in the pessimistic scenario.

\section{Designing and implementing an effective response}

This section outlines institutional recommendations to design and implement an effective policy response. It also puts forward specific policy recommendations, many of which are already being tested throughout the region.

\footnotetext{
6 These countries do not fare so well when the long term human capital effects of school closings are taken into consideration, as shown in Lustig, Neidhöfer and Tommasi (2020).
} 


\section{Institutional recommendations}

As discussed above, many Latin American communities and groups are facing several simultaneous disadvantages. In other words, they suffer from multidimensional poverty. These pre-existing situations are worsened by the COVID-19 pandemic, which threatens not only their lives and livelihoods, but also their human capital. Modern human development theory recognizes that people's lifetimes include critical events that might affect them forever - such as a house fire, death of a family member, inadequate health care during pregnancy, child malnutrition, traumatic experiences, teen pregnancy, violence in the home, drug use and school dropout. Given the existence of multiple reinforcing dimensions of deprivation, and considering the risks of such disruptive life events, it is incredibly important that -in normal times and even more so during the current emergency - public interventions are able to focus on supporting these vulnerable population groups. For the most vulnerable people, general top-down policies are not enough. They must be accompanied by coordinated efforts that focus on the specific risks faced by each community, each family and each individual. Expressed in public policy jargon, coordination across government sectors and focus on individual and local circumstances are essential.

The question is how best to achieve such coordination and focus from an organizational point of view. There are two essential institutional functions that need to be carried out for the effective design and implementation of policies targeting the most vulnerable. First, there must be a physical and social proximity with vulnerable communities to ensure their trust, and to mediate between the specific needs of the community (and families and people) and the wide and disorganized range of public programmes. Second, there must be sufficient coordinating or persuasive capacity with regards to central agencies, ministries and programmes in order to attend to the particular needs of a given community.

Different governmental structures might fulfil such institutional functions. Various Latin American countries have governmental units that are in line with this rationale to some extent. Generally speaking, however, two steps are necessary: first, identify which existing government structures best fulfil these functions; and second, endow them with the adequate resources and political backing at the highest level (the Office of the President in most Latin American countries).

In the longer version of this article, we detail actors, roles and recommendations at various layers from senior government to field level. For brevity, we will mention the functions corresponding to three crucial layers: (i) the agency responsible for assisting the most vulnerable populations; (ii) the relevant territorial units in each poor neighbourhood and community; and (iii) the local networks and organizations involved in grass-roots implementation.

(i) Ideally, the coordination of all State efforts aimed at providing social support to poor neighbourhoods and communities should be coordinated by an agency responsible for this task. This agency should adjust all general policies (dissemination of information, epidemic control, income transfers, food, health, security and education) to the particular needs of these communities. It should demand that the relevant ministries implement any additional measures required. One example would be the education provision for populations with limited Internet access. Such an agency should also coordinate the territorial units in each neighbourhood. By means of territorial units, the entity should gather information on the general and specific needs of these populations.

(ii) The main tasks of the territorial units within each poor neighbourhood are as follows:

- Coordinating the local implementation of all interventions from the national and local levels.

- Involving neighbourhood networks and local organizations (NGOs, churches and social movements) in identifying specific urgencies and priorities.

- Enhancing the networks of local social actors. 
(iii) The engagement of local grass-roots actors is crucial for ensuring that interventions are effective and appropriately targeted. Monetary and non-monetary interventions are crucial for those living in poverty and vulnerable situations. These include food, clothing, medical and educational assistance and emotional support, to name but a few. State agencies must rely on local actors that are aware of the specific needs of each individual child, adolescent mother, at-risk youth and survivor of violence in the home, as well as knowing when such essential help is needed.

We add a fourth recommendation related to the allocation of resources.

(iv) Every action suggested has major budgetary implications. The extremely dire current situation requires a courageous reallocation of resources. Our main claim in that regard is that we need to allocate more resources to protect the lives, livelihoods and human capital of the poorest. With regard to the institutional recommendations in this section, this implies:

- allocating more resources to governmental units that focus on the most vulnerable; and

- channelling part of the distribution of support and services through NGOs and grass-roots social organizations, and allocating the necessary budget.

We hasten to add that, even though budgetary resources are needed, part of these objectives can be fulfilled with political decisions and institutional focus. ${ }^{7}$

\section{Specific recommendations}

In addition to the above-mentioned broad recommendations, this section includes a set of specific recommendations for various stages of the pandemic's cycle. We classify them into two main categories: reducing exposure to epidemiological risk; and protecting livelihoods, human capital and the provision of basic services.

\section{(a) Reducing exposure to the epidemiological risk of illness and death}

During the state of emergency:

- Design suitable communication strategies. Information campaigns should be as transparent as possible and match the realities of the target audience.

- Plan strategies that involve marginalized groups in urban areas and indigenous communities. Authorities should prevent the virus from spreading, while avoiding any sort of discrimination along the way.

- Guarantee access to clean water, soap and other essential products - such as masksthat are needed for prevention.

- Guarantee access to income, food and basic necessities. This is crucial for making the stay-at-home restrictions viable.

- Ensure connectivity in marginalized areas. This is essential to enable people to communicate with support networks in real time, report violence or crime, provide alternative activities for children and youth and, in some cases, to facilitate some income-generating activities. This might include providing some equipment to key representatives within the community.

\footnotetext{
7 Successful implementation is less expensive than it may appear. It requires energetic and determined political action to change some bureaucratic incentives. This applies to several policies other than cash transfers, such as protecting women from domestic violence or targeting interventions to avoid child malnutrition.
} 
- Use spaces other than hospitals, such as schools or hotels, to successfully isolate COVID-19 patients or those exhibiting similar symptoms.

- Design strategies to safely move patients in need of special medical care from one medical facility to another. This means that additional funds should be invested in transport such as ambulances - particularly in rural areas.

After the state of emergency:

- Give free access to COVID-19 tests to the poorest and most vulnerable groups in society.

- Continue to open new isolation centres to allow people who may be infected to be isolated.

- Guarantee access to safe drinking water.

- Make sure that marginalized groups own technology devices that allow them to be tracked. This will help avoid a new COVID-19 upsurge, as well as improving all-round communication through connectivity.

- Financial inclusion based on information and communications technologies (ICTs). Granting access to bank services and debit cards will not only make transfers more efficient but will also give authorities an inside view of the economic impact of the virus outbreak.

\section{(b) Protecting livelihoods, human capital and the provision of basic services}

\section{Access to income, food and services}

- Transfers. We recommend providing monetary transfers that allow those living in poverty to reach a minimum consumption level, especially for those people not covered by previous programmes. One additional alternative is the use of food coupons (more recently, debit cards, to be used for purchasing food).

- Temporary employment programmes. We recommend hiring the currently unemployed workforce to do tasks requiring similar skills in the sectors that have high demand today, such as sanitizing transport vehicles or public spaces, guarding and providing various services to hospitals and doctors or working on food distribution.

- Direct food distribution. Attention should be given to optimizing the protocols and materials to minimize human contact. This should be done by supporting existing grass-roots organizations.

- Tax cuts or deferrals. For instance, taxes on international transfers or remittances (below a certain amount) should be temporarily eliminated.

- Prevent vulnerable households from having basic services like water, electricity and Wi-Fi disconnected.

Mitigation of violence in the home. Additional policies to deal with violence in the home should be rapidly designed and executed. Standard procedures should be implemented to identify and prevent violent episodes. For instance, victims must be guaranteed access to confidential spaces to alert authorities. Here again, grass-roots organizations and local networks should be key players, and local government officials should be made accountable for implementing quick solutions.

Continued education. Education must be continued through TV or radio while connectivity is not an option for some families. Communication companies should begin to offer special packages as part of their services in order to allow free or subsidized wireless Internet services for educational use. Vulnerable children at the edge of society should be the focus of strategies to ease restrictions. 
Ensured access to health and medication beyond COVID-19. Adequate protocols are essential to isolate patients with potential COVID symptoms. However, regular vital health-care services should continue to be provided (including vaccinations, treatment of infectious diseases, care of sexual and reproductive issues including contraception, medicines for chronic and mental illness, emergency surgery and care for victims of violence and accidents). The services offered by existing neighbourhood primary health-care units should be enhanced, including the extension of operating hours.

Consideration for particularly vulnerable groups. The impact of crises such as this is twice as devastating for groups that, in addition to living in poverty, suffer from specific problems or risks. These include children, at-risk youth, undocumented migrants or people who are transgender, homeless or in prison. Throughout Latin America, some non-profit organizations play a key role in easing and addressing their difficulties. Those efforts should be supported and promoted.

\section{Concluding remarks}

Given the interconnections between the various dynamics of the pandemic, it is crucial to integrate epidemiological, economic and social strategies under a consistent overarching umbrella. The well-being of the poorest and most vulnerable people in society should be prioritized, with the three goals of preserving lives, livelihoods and human capital. This is imperative not only for humanitarian reasons, but also to minimize the impact of epidemiological and economic externalities - as well as social and political risks. The poorest and most vulnerable groups require special attention not only in terms of income support but also in terms of the whole array of actions directed to their overall well-being. It is vital to complement general policies (health, education, security and connectivity) with special actions targeting vulnerable groups. This requires urgent action in the short term, as well as strategic investments in the medium term. In the short term, it is crucial to maintain access to incomes, food and health care, as well as implementing decisive actions to prevent the negative consequences of the pandemic (such as the rise in violence - especially violence in the home-). In the medium term, it is fundamental to invest in connectivity services and identify actions to ensure that poor children are able to make up for lost schooling and do not drop out.

When designing interventions, it is vital to take into account the specificities and levels of heterogeneity across and within vulnerable groups. To do that, it is important to build on local social networks and to make use of non-governmental actors that work in close proximity to these groups.

\section{Bibliography}

Albertos, C. (2018), "Desarrollo sostenible de los pueblos indígenas: con ellos, para ellos”, Mejorando Vidas, Inter-American Development Bank (IDB) 9 August [online] https://blogs.iadb.org/igualdad/es/desarrollosostenible-de-los-pueblos-indigenas-con-ellos-para-ellos/.

Azevedo, J. P. and others (2020), "Simulating the potential impacts of COVID-19 school closures on schooling and learning outcomes: a set of global estimates", Policy Research Working Paper, No. 9284, Washington, D.C., World Bank.

CEDLAS (Center of Distributive, Labor and Social Studies)/World Bank (2020), Socio-Economic Database for Latin America and the Caribbean (SEDLAC), May [online] https://www.cedlas.econo.unlp.edu.ar/wp/ en/estadisticas/sedlac/.

CRC (Coronavirus Resources Center) (2020), "Mortality analyses", Johns Hopkins University \& Medicine [online] https://coronavirus.jhu.edu/data/mortality.

ECLAC (Economic Commission for Latin America and the Caribbean) (2020a), CEPALSTAT [online database] http://interwp.cepal.org/cepalstat/portada.html?idioma=english. 
(2020b), "Addressing the growing impact of COVID-19 with a view to reactivation with equality: new projections", COVID-19 Special Report, No. 5, Santiago, July.

FAO/ECLAC (Food and Agriculture Organization of the United Nations/Economic Commission for Latin America and the Caribbean) (2020), "Food systems and COVID-19 in Latin America and the Caribbean: food consumption patterns and malnutrition", Bulletin, No. 10, July [online] https://www.cepal.org/en/ publications/45795-food-systems-and-covid-19-latin-america-and-caribbean-ndeg-10-food-consumption.

IHME (Institute for Health Metrics and Evaluation) (2020), "Correction: new IHME COVID-19 model forecasts Latin American, Caribbean nations will see nearly 440,000 deaths by October 1", 25 June [online] http:// www.healthdata.org/news-release/correction-new-ihme-Covid-19-model-forecasts-latin-americancaribbean-nations-will-see.

Kessler, G. (coord.) (2020), Relevamiento del impacto social de las medidas del aislamiento dispuestas por el PEN, Buenos Aires, Social Sciences Commission, COVID-19 Unit, March.

Lustig, N. and M. Tommasi (2020), El COVID-19 y la protección social de los grupos pobres y vulnerables en América Latina, Buenos Aires, Centro de Estudios para el Desarrollo Humano (CEDH), San Andrés University/Commitment to Equity Institute (CEQI), Tulane University, May.

Lustig, N., G. Neidhöfer and M. Tommasi (2020), "Short and long-run distributional impacts of COVID-19 in Latin America", CEQ Working Paper series, No. 96, Commitment to Equity (CEQ) Institute, Tulane University, October.

Lustig, N. and others (2020), "The impact of COVID-19 lockdowns and expanded social assistance on inequality, poverty and mobility in Argentina, Brazil, Colombia and Mexico", Covid Economics, Vetted and Real-Time Papers, No. 46, Centre for Economic Policy Research (CEPR), September.

PAHO (Pan American Health Organization) (2020), Health Information Platform for the Americas (PLISA) [online database] https://www.paho.org/data/index.php/en/.

UN-Women (United Nations Entity for Gender Equality and the Empowerment of Women) (2020), "COVID-19 and ending violence against women and girls", EVAW COVID-19 Briefs, New York, May.

WFP (World Food Programme) (2020), "Hunger rises as Covid-19 cases surge in Latin America", Rome, 29 July [online] https://www.wfp.org/news/hunger-rises-covid-19-cases-surge-latin-america. 